\title{
Scanning Electron Microscopy of Six Selected Mealybug (Hemiptera: Pseudococcidae) Species of Sri Lanka
}

\author{
U.G.A.I. Sirisena* , G.W. Watson ${ }^{1}$, K.S. Hemachandra ${ }^{2}$ \\ O. Sage ${ }^{1}$ and H.N.P. Wijayagunasekara ${ }^{2}$ \\ Postgraduate Institute of Agriculture \\ University of Peradeniya \\ Sri Lanka
}

\begin{abstract}
The Scanning Electron Microscope (SEM) is extremely useful for studying the detailed morphology of very small structures on insect cuticle, enabling quick and accurate representation. Scanning electron microscopy of mealy bugs (Hemiptera: Pseudococcidae) is challenging, due to the thinness and flexibility of the cuticle. The threedimensional structure of the wax-producing pores of mealy bugs is complicated and can be best elucidated using the SEM. Only a few studies have reported on ultra structure and waxsecretion processes in the Pseudococcidae. The aim of this study was to enrich the understanding of the external morphology and wax-secreting pores of mealy bugs, using scanning electron microscopy. Six economically important pest mealy bug species in Sri Lanka were studied under the SEM namely, Coccidohystrix insolita (Green), Dysmicoccus brevipes (Cockerell), D. neobrevipes Beardsley, Maconellicoccus hirsutus (Green), Phenacoccus solenopsis Tinsley and Planococcus lilacinus (Cockerell). The specimens were subjected to dehydration, critical point drying and sputter coating, before being scanned using the SEM. The ultra structure of the antenna, ostiole, vulva, claw digitules, cerarius, circulus and wax-secreting pores were examined. Wax-secreting pores of different species showed remarkable structural variation. Minute characters of taxonomic importance that can only be seen under the SEM are discussed. Although the preparation of specimens for viewing under the SEM is time-consuming and expensive, the effort is worthwhile because the detailed information obtained may solve some difficult aspects of mealy bug taxonomy, and help to improve the understanding of the role of wax secretions in mealy bug biology.
\end{abstract}

Keywords: Mealybugs, morphology, structural variation, wax-secreting pores

\section{INTRODUCTION}

The Scanning Electron Microscope (SEM) is extremely useful for studying the detailed morphology of very small structures on insect cuticle. In the past, long hours of careful artistic labour were required to accurately illustrate structures of insects for use in identification; now the SEM enables quick, accurate representation. The SEM is superior to a conventional compound light microscope in having: (1) higher resolution, (2) threedimensional clarity, and (3) great depth of field. The rigid exoskeleton of insects is especially suitable for electron microscopy because the specimen usually retains its shape under

\footnotetext{
California Department of Food and Agriculture, Plant Pest Diagnostic Center, Sacramento, California, USA

Department of Agricultural Biology, Faculty of Agriculture, University of Peradeniya, Sri Lanka

Corresponding author: anuraindra@gmail.com
} 
vacuum. In some cases, beetles with extremely hard exoskeletons can be viewed alive for short periods of time (Legner and Kogan, 1969).

Scanning electron microscopy is increasingly being used by forensic entomologists, to obtain details of dipteran egg and larval morphology (Ubero-Pascal et al., 2010). Ammar et al. (2013) used SEM for ultrastructural studies on the honeydew and waxy secretions of the woolly oak aphid (Hemiptera: Aphididae: Stegophylla brevirostris Quednau). Scanning electron microscopy of mealy bugs is more challenging, due to the thinness and flexibility of the cuticle, necessitating careful critical-point drying to avoid crumpling and distortion. The SEM provides an excellent and detailed morphological overview (Pease et al., 1966; Howden and Ling, 1973; Reese and Carlson, 1974; Zhang et al., 2012), but is rather expensive and requires specialized preparation of the material to be studied (Ubero-Pascal, 2010).

In mealy bugs, waxes produced by different dermal pores are important in protecting different developmental stages. Wax on the body surface may prevent contamination by honeydew (Broadbent, 1951; Cox and Pearce, 1983; Pope, 1983) or invasion of the body by bacteria, fungi and other parasites (Foldi and Pearce, 1985); or prevent damage at the point where eggs touch, so facilitating hatching (Hashimoto and Ueda, 1985). Hydrophobic properties of wax filaments in the ovisac may prevent insecticides from reaching the eggs within (Mani, 1986; Dhahira, 1991; Manjunatha et al., 1993).

The mealy wax covering on the integument of mealy bugs differs from that of other insects in many ways. Its presence on the surface is well documented, but there has been only limited speculation on its function, or on reasons for the variety of pores and ducts found within a single species (Waku and Manabe, 1981; Cox and Pearce, 1983; Foldi and Cassier, 1985; Bielenin and Weglarska, 1990; Foldi and Lambdin, 1995). The structure of the waxproducing pores is complicated and can be elucidated better using the SEM. However, only a few studies have reported on the ultrastructure and wax-secretion processes in the family Pseudococcidae (Cox and Pearce, 1983; Kumar et al., 1997; Jansen, 2001; Vahedi and Mahfar, 2010).

Cook et al. (2000) used the SEM to study crawler sexual dimorphism in species in the scale insect family Eriococcidae. The spermatozoa of mealy bugs were studied under the SEM by Doutt (1949) for use in the classification of mealy bugs; he found that some characters could only be seen under the SEM. In China, early research using the SEM focused on the white wax scale insect, Ericerus pela Chavannes (Hemiptera: Coccidae) (Zhang et al., 1988; Tan and Zhang, 1992). Likewise, a few studies reported on the ultra structure and wax-secretion processes in the family Pseudococcidae. There has not been any study of the ultra structure of Sri Lankan mealy bugs, so this work was conducted to enrich the understanding of the external morphology and wax glands of six economically important species from Sri Lanka, using scanning electron microscopy.

\section{METHODLOGY}

This study was conducted at the Department of Agricultural Biology, Faculty of Agriculture, University of Peradeniya, Sri Lanka and the Plant Pest Diagnostic Centre, California Department of Food and Agriculture, Sacramento, California, USA during 2011-2014. Mealy bugs were collected from different agro-ecological zones of Sri Lanka during the study period. Six mealy bug pests were studied: Coccidohystrix insolita (Green), 
Dysmicoccus brevipes (Cockerell), D. neobrevipes Beardsley, Maconellicoccus hirsutus (Green), Phenacoccus solenopsis Tinsley and Planococcus lilacinus (Cockerell).

Dehydration of the Specimens: Adult female mealy bugs, killed and stored in $70 \%$ ethanol for three months, were dehydrated gradually by a series of 1-hour soaks through a succession of increasing concentrations of ethanol $(75,80,85,90,95$, and $100 \%$ ethanol $[\mathrm{v} / \mathrm{v}])$, gradually replacing water in the specimens with liquids with lower surface tensions, without distorting them. Then they were immersed in Chloroform for $1 \mathrm{hr}$ to dissolve the surface wax, finishing with a final rinse in $100 \%$ ethanol (from a newly opened bottle, to ensure no water was present).

Critical Point Drying: For each species, specimens in 5-10 ml of 100\% ethanol were placed in the high-pressure chamber of a critical-point dryer (Tousimis Samadri-780A). A flow of liquid carbon dioxide $\left(\mathrm{CO}_{2}\right)$ into the specimen chamber was maintained for 60-90 seconds at 0-10 ${ }^{\circ} \mathrm{C}$ and 850-900 psi. After its transition from the liquid to the gas phase at the critical point (approximately $1,200 \mathrm{psi}$ and $31{ }^{\circ} \mathrm{C}$ ), the $\mathrm{CO}_{2}$ escaped, by which time the specimen had been completely dried without any structural damage or distortion. Each dehydrated specimen was then glued onto a standard SEM stub (diameter $12.5 \mathrm{~mm}$, height $3.0 \mathrm{~mm}$ ) using double-sided sticky tape (Anon., 2005).

Sputter Coating: To prevent the electron beam burning a hole through the cuticle, each specimen must be coated with a protective, reflective surface. Sputter coating covers the specimen with a very thin layer of heavy metal (gold-palladium mixture). Each specimen was placed in the sputter chamber (Hummer 6.2, Anatech Ltd); the air pumped out and replaced with nitrogen gas, before a plasma of metal molecules was released for 3.5-4.0 minutes to coat the specimen with metal (Anon., 1993).

Use of the SEM: A fully computer-controlled scanning electron microscope (VEGA3 SEM, TESCAN) with a tungsten heated filament was used to scan each gold-paladium-coated specimen in turn. A specimen was sealed in the SEM chamber and the air was evacuated. Using high vacuum, it was scanned with the electron beam at $30 \mathrm{kV}$ from different angles. Images of mouthparts, ostioles, vulva, claw digitules, cerarii, and different types of wax pore were taken using the VEGA3's SE detector (Anon., 2010).

\section{RESULTS AND DISCUSSION}

Micrographs of external morphological characters of mealy bugs (antenna, ostiole, vulva, digitules, cerarius, circulus and wax-secreting pores) are shown in Figs 1 and 2.

Antenna: Eight antennal segments were present in Dysmicoccus brevipes, D. neobrevipes (Fig. 1a) and Planococcus lilacinus; Coccidohystrix insolita, Maconellicoccus hirsutus and Phenacoccus solenopsis each had 9 antennal segments. Separation between the apical and sub apical segments is clear; the apical segment is the longest, followed by the third and second segments. Antennal setae are very conspicuous: the non-apical flagellar segments each have 2-5 setae; the 2 pre-apical segments each bear an additional, fleshy sensory seta; and the apical segment has 10-12 flagellate setae, 3 fleshy setae and 6 stiff setae near the apex. Early workers used the number of antennal setae as primary characters to separate species (e.g. Maskell, 1894; Essig, 1909; Smith, 1911; and Hollinger, 1917). The overall length of the antenna, as well as the lengths of the individual segments, were recorded in detail by numerous workers until Ferris (1918) decided that variation made is unreliable as a 
taxonomic character. However, the setae associated with the antennal segments, clearly visible under the SEM, might be useful for separating closely related species.

Legs: Adult female mealy bugs have only one tarsal segment and a single claw on each leg. At the expanded base of the claw, there is usually a pair of seta-like digitules (claw digitules), which are either shorter or longer than the claw, and either pointed or expanded distally. Normally a pair of tarsal digitules is also present at the apex of each tarsomere. Although claw digitules are visible under the compound light microscope at high magnifications, tarsal digitules are often difficult to see. Both tarsal and claw digitules were clearly visible under the SEM. Fig 1d, 1e and 1f show claw digitules of Pl. lilacinus, $D$. neobrevipes, and $P h$. solenopsis respectively. All were knobbed at the apex, except the tarsal digitule of Ph. solenopsis, which was setose. Claw digitules were slightly longer than the claw and thicker than the tarsal digitules in all six species.

A small tooth or denticle was present on the plantar surface of the claw in $C$. insolita (Fig. $1 \mathrm{~g}$ ) and $\mathrm{Ph}$. solenopsis. The presence of a denticle is taxonomically significant, as it is correlated with a suite of other characters used for the recognition of several genera related to the genus Phenacoccus (Ferris, 1950).

Fig. 1b shows the campaniform sensilla on the trochanter of D. neobrevipes. These mechanoreceptors are found in mealy bugs and other insects. Each sensillum appears as an elliptical depression of the cuticle with a slightly raised, oval inner area. The campaniform sensilla are presumably activated when the surrounding cuticule becomes distorted by mechanical stress. It is thought that the extent of flexion at the joints is monitored by the campaniform sensilla (Okada, 2009).

Ostioles: Paired ostioles are a diagnostic feature of the family Pseudococcidae. Each ostiole is a lip-like cuticular structure on the dorsum. The SEM view (Fig. 1c) shows an outer pair of 'lips' of epicuticle, surrounding an inner pair of membranous 'lips'. The inner 'lips' form a muscularly controlled valve at the outer end of an internal canal. When a mealy bug is disturbed or irritated, the inner 'lips' may be relaxed to release a globule of liquid that congeals quickly on contact with the air; this is believed to be a defensive mechanism, fouling the mouthparts of a predator (Cox, 1987). The outer lips bear trilocular pores and sometimes flagellate setae (Fig. 1c), probably to prevent the exudates fouling the mealy bug's surface (Cox, 1987). In some species, the number of ostioles may be reduced or entirely lacking: for example, in Rastrococcus iceryoides (Green) the posterior pair is present but the anterior pair is missing.

Cerarii: These paired, dorsal structures on the body margins are present only in mealy bugs; they secrete and support the lateral wax filaments in life (Cox and Pearce, 1983). Each cerarius consists of an aggregation of setae of one or two types, trilocular pores, and sometimes discoidal pores. Glassy wax filaments are secreted from the bases of the enlarged, conical setae, forming the core of the lateral wax filament, and powdery wax from the trilocular pores bulks it out (Cox and Pearce, 1983). In D. neobrevipes (Fig. 1h), each cerarius usually contains more than two conical setae and an aggregation of trilocular pores, while in Ph. solenopsis (Fig. 1i) each has only two conical setae and an aggregation of trilocular and a few simple pores. Coccidohystrix insolita has similar structures in the midregion of the dorsal surface too (although these dorsal cerarii, with multiple conical setae, lack trilocular pores); they secrete the glassy wax filaments that protrude from live $C$. insolita. 

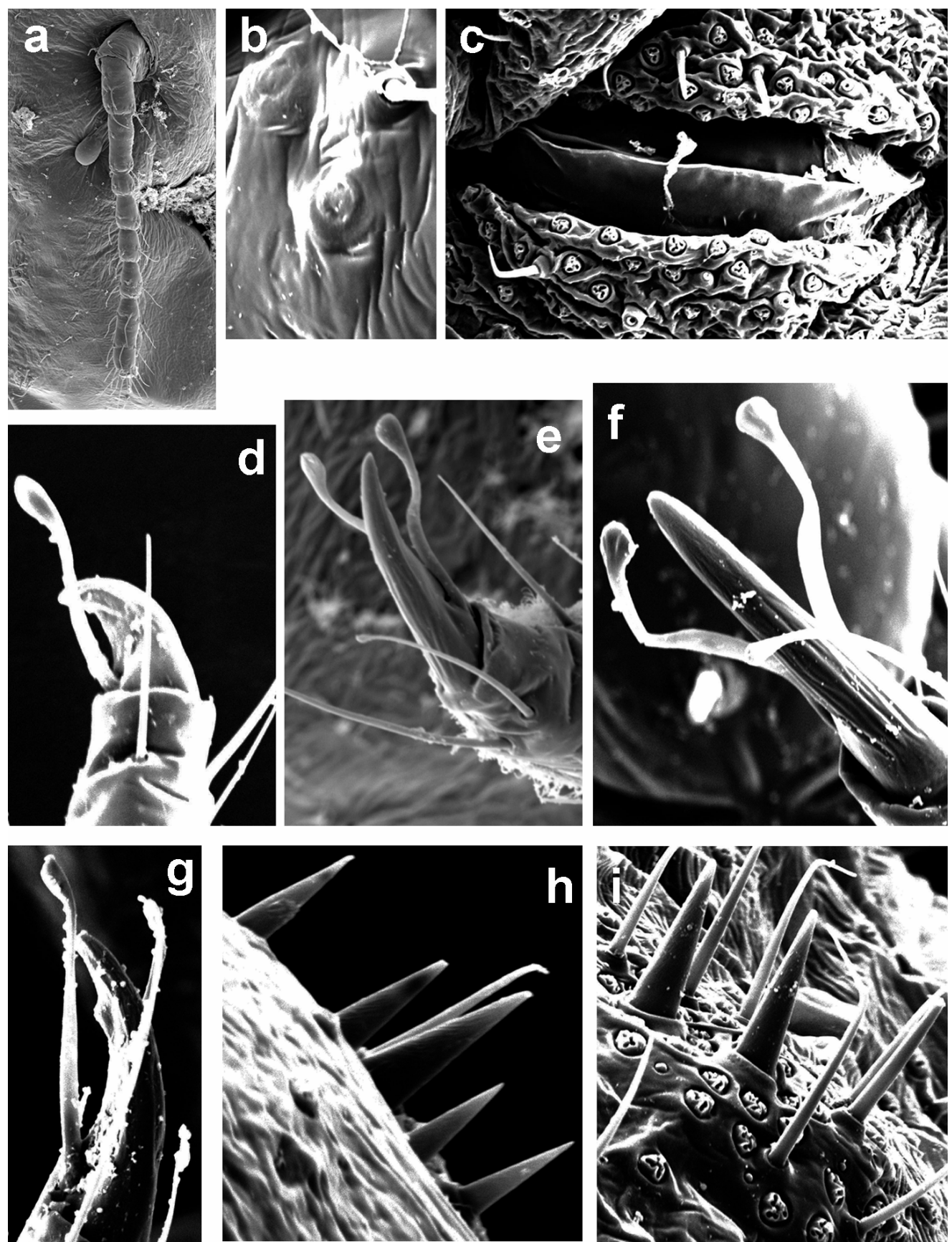

Fig. 1. Scanning electron micrographs of cuticular structures of mealy bugs. (a) Antenna of Dysmicoccus neobrevipes; (b) campaniform sensilla of $D$. neobrevipes; (c) ostiole of $D$. brevipes; digitules of (d) Planococcus lilacinus, (e) D. neobrevipes and (f) Phenacoccus solenopsis; (g) denticle of Coccicohystrix insolita; cerarius of (h) D. neobrevipes and (i) Ph. solenopsis. 
Circulus: The circulus is a large, membranous structure found on the midline of the abdominal venter in many mealybug species; it helps the mealybug adhere to the substrate. Circuli are present only in mealybugs, but the cicatrices in some Margarodidae sensu lato may be homologous. The SEM showed that the circulus is a flexible, button-like structure (Fig. 2a); the cuticular folds suggest that it can be somewhat projected from the venter by internal hydraulic pressure due to muscular contraction. Circuli of a variety of shapes and sizes occur in different species, and may be present or absent; in Ph. solenopsis (Fig. 2a), it is oval with a small indentation on each side, with a crease across the intersegmental line, whereas in M. hirsutus it is quadrate and apparently lacks an intersegmental crease (Fig. 2b).

Wax pores: Differences in wax pore ultrastructure may be taxonomically useful. Such differences have been used to revise the generic placement of some scale insect species into families, such as Coccidae, Diaspididae and Monophlebidae (Takagi, 1990; Ülgentürk and Wilhem, 2001; Unruh, 2008; Unruh and Gullan, 2008).

Each quinquelocular pores consist of a pentagonal, raised area of cuticle containing a circle of five openings or loculi. Relatively few genera of mealy bugs have quinquelocular pores; in the six species examined only $C$. insolita possessed them (Fig. $2 \mathrm{~g}$ ).

Multilocular disc pores are usually present on the venter, at least around the vulva; sometimes they may be present also on the dorsum. Each pore contains a circle of more than five openings (loculi); in M. hirsutus, the outer ring contained 8-10 loculi. The wax curls produced by the multilocular pores surrounding the vulva become attached to each egg as it leaves the genital opening (Kumar et al., 1997).

These wax curls may become incorporated in the ovisac in oviparous species (Cox and Pearce, 1983). In C. insolita, multilocular disc pores are abundant on the venter, around the vulva and across the abdominal segments as far forward as segment I. In D. brevipes and $D$. neobrevipes, multilocular pores are concentrated around the vulva (Figs $2 \mathrm{~d}$ and $2 \mathrm{e}$ ). Fig. $2 \mathrm{e}$ shows flattened wax strips emerging from a multilocular disc pore, one strip from each loculus.

Trilocular pores produce spiral wax filaments that fragment to form the fine, mealy body covering (Cox and Pearce, 1983). These pores are usually abundant and evenly distributed over both dorsum and venter; each consists of a rounded-triangular raised area containing three elongate, narrow openings radiating from the centre of the pore and slightly twisted, or swirled, about each other. In M. hirsutus, each trilocular pore is situated in a circular depression and contains three separate, dumb-bell-shaped loculi (Fig. 2h). In D. neobrevipes, each pore has a similar arrangement of loculi, but is not situated in a circular depression (Fig. $2 \mathrm{i})$. In contrast, the loculi in the trilocular pores of $D$. brevipes are boomerang-shaped and connect in the centre (Fig. $2 \mathrm{j}$ ), and the pore is situated in a slightly triangular depression. 

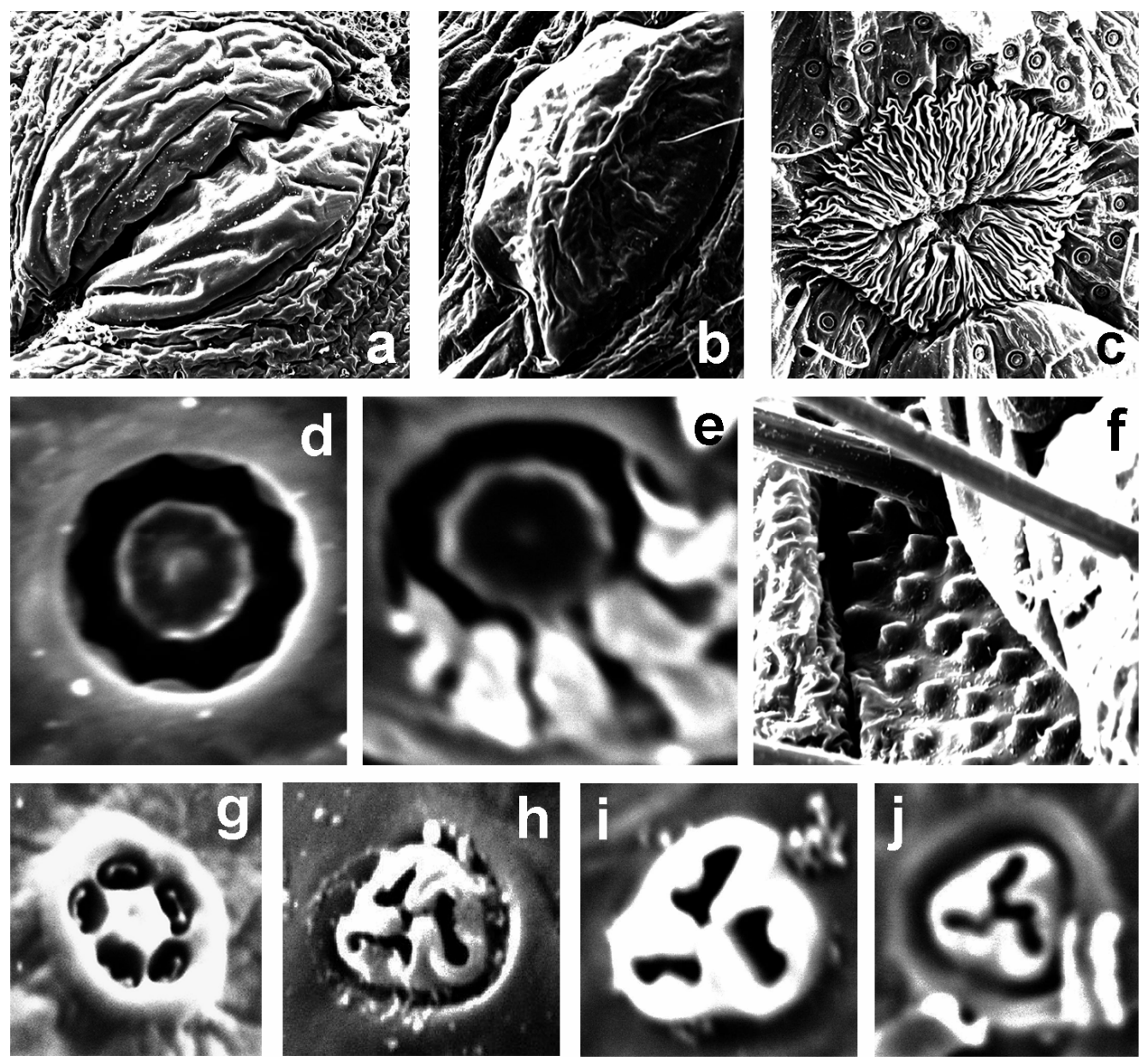

Fig. 2. Scanning electron micrographs of cuticular structures of mealybugs. Circulus of (a) Maconellicoccus hirsutus and (b) Phenacoccus solenopsis; (c) vulva of Coccidohystrix insolita; multilocular disc pore of (d) Dysmicoccus brevipes and (e) D. neobrevipes; (f) detail of the anal ring of M. hirsutus; (g) quinquelocular pore of C. insolita; trilocular pore of (h) M. hirsutus, (i) D. neobrevipes and (j) D. brevipes.

\section{CONCLUSIONS}

The scanning electron microscope is a very useful tool for observing minute, threedimensional structures of mealy bugs, and some of these details can only be seen under the SEM. Although the preparation of specimens for viewing under the SEM is time-consuming and expensive, the effort is worthwhile because the detailed information obtained is useful to solve some difficult aspects of mealy bug taxonomy, and to improve understanding the role of wax in their biology. 


\section{ACKNOWLEDGEMENTS}

This project was made possible by funding from the World Bank through the Higher Education for the Twenty-first Century (HETC) project (grant no. RUSL/O-Agri/N2), Ministry of Higher Education of Sri Lanka. The authors thank Ms Susan McCarthy, Branch Chief, California Department of Food and Agriculture Plant Pest Diagnostic Centre, Sacramento, California, USA, for use of the SEM at this facility.

\section{REFERENCES}

Ammar, E.D., Alessandro, R.T. and Hall, D.G. (2013). Ultrastructural and chemical studies on waxy secretions and wax-producing structures on the integument of the woolly oak aphid Stegophylla brevirostris Quednau (Hemiptera: Aphididae). J. Microsc. Ultrastruct., 1, 43 50 .

Anonymous (1993). Cyber extension: Hummer 6.2 user's manual. Anatech Ltd. [on line]. [Accessed on 24.07. 2014]. Available at:

http://my.fit.edu/ mzhang/nanolab/hummer_man.pdf

Anonymous (2005). Cyber extension: Instructions for sample drying at the critical point: Tousimis critical point dryer, "Samdri-780A". University of Minnesota Characterization Facility publication. [on line]. [Accessed on 24. 07. 2014]. Available at: http://www.charfac.umn.edu/instruments/prep_samdri-780_instructions.pdf

Anonymous (2010). Cyber extension: VEGA3 SEM scanning electron microscope, instructions for use. TESCAN, a.s. Brno, Czech Republic. [on line]. [Accessed on 24. 07. 2014]. Available at:

http://www.ualberta.ca/ACSES/ACSES3/instrumentation/instruments/Vega3_files/VEGA_m anual_GEN_3_04_tisk.pdf

Bielenin, I. and Weglarska, B. (1990). Study of the epidermal glands of female Gossyparia spuria (Mod.) (Coccoidea, Eriococcidae) and SEM morphology of secreted waxes. Zool. Jahrb., 120(04), 369 - 379.

Broadbent, L. (1951). Aphid excretion. Poc. R. Entomol. Soc. Lond., 26, 97 - 103.

Cook, L.G. Gullan, J.P. and Stewart A.C. (2000). First-instar morphology and sexual dimorphism in the gall-inducing scale insect Apiomorpha Rubsaamen (Hemiptera: Coccoidea: Eriococcidae). J. Nat. Hist. 34, 879 - 894.

Cox, J.M. and Pearce, M.J. (1983). An experimental study of morphological variation in mealy bugs (Homoptera: Coccoidea: Pseudococidae). Syst. Entomol., 8, 361 - 382.

Cox, J.M. (1987). Pseudococcidae (Insecta: Hemiptera). Fauna of New Zeal., 11, 1 - 232.

Dhahira, B.N. (1991). Mulberry mealy bug - a hard-to-kill pest. Indian Silk, 30, 34.

Doutt, R.L. (1949). The spermatozoon as a diagnostic tool in mealy bug taxonomy. J. Econ, Entomol., 42(05), 835. 
Essig, E.O. (1909). The genus Pseudococcus in California. Pomona Coll. J. Entomol. 1, 35 46.

Ferris, G.F. (1918). The alleged occurrence of a seasonal dimorphism in the females of certain species of mealy bugs (Hemiptera; Coccidae). Entomol., News 29, 349 - 352.

Ferris, G.F. (1950). Atlas of the Scale Insects of North America. Series V. The Pseudococcidae (Part I), pp. 278. Stanford University Press, Stanford, California, USA.

Foldi, I and Cassier, P. (1985). Ultrastructure comparée des glands tegumentaires de treize families de cochenilles (Homoptera: Coccoidea). Int. J. Insect Morphol. Embryol. 14, 33 50 .

Foldi, I. and Lambdin, P.L. (1995). Ultrastructural and phylogenetic assessment of wax glands in pit scales (Homoptera: Coccoidea). Int. J. Insect Morphol. Embryol., 24, 35 - 49.

Foldi, I. and Pearce, M.J. (1985). Fine structure of wax glands, wax morphology and function in the female scale insect, Pulvinaria regalis Canard (Hemiptera: Coccidae). Int. J. Insect Morphol. Embryol., 14, 259 - 271.

Hashimoto, A. and Ueda, M. (1985). Coil form wax on the egg surface of Drosicha corpulenta Kuwana (Homoptera: Margarodidae) Appl. Entomol. Zool., 20, 92 - 93.

Hollinger, A.H. (1917). Taxonomic value of antennal segments of certain Coccidae. Ann. Entomol. Soc. America, 10, 264 - 271.

Howden, H.F. and Ling, C.E.C. (1973). Scanning electron microscopy: low magnification pictures of uncoated zoological specimens. Science, 179, 386 - 388.

Jansen, M.G.M. (2001). Instar identification and some notes about the life cycle of Rhizoecus hibisci Kawai and Takagi (Coccoidea: Pseudococcidea). In: Proceedings of the IX International Symposium on Scale Insect Studies (ed. G. Pellizzari). Boll. Zool. Agr. e di Bachicoltura, 33(03), 53 - 66.

Kumar, V., Tewari, S.K. and Datta, R.K. (1997). Dermal pores and wax secretion in mealybug Maconellicoccus hirsutus (Hemiptera, Pseudococcidae). A pest of mulberry. Ital. J. Zool., 64(04), 307 - 311.

Legner, E.F. and Kogan, M. (1969). Scanning electron microscope: offers new techniques for diagramming diagnostic characters on insects. California Agric., 23(09), 4-5, DOI: 10.3733/ca.v023n09p4.

Mani, M. (1986). Distribution, bio ecology and management of the grape mealy bug Maconellicoccus hirsutus (Green) with special reference to its natural enemies. PhD thesis, University of Agricultural Sciences, Bangalore, India.

Manjunatha, D. Kumar, P. Kishore, R. Prasad, S.K. Narayanaswamy, K.C. and Datta, R.K. (1993). Towards understanding tukra and its management. Indian Silk 32, 6 - 9.

Maskell, W.M. (1894). Further coccid notes with descriptions of several new species and discussion of various points of interest. Trans. Proc. New Zeal. Inst., 26, 65 - 105. 
Okada, J. (2009). Cockroach antennae. Scholarpedia, 4(10), 6842.

Pease, R.F.W. Hayes, T.L. Camp, A.S. and Amer, N.M. (1966). Electron microscopy of living insects. Science, 154,1185 - 1186.

Pope, R.D. (1983). Some aphid waxes, their form and function (Homoptera: Aphididae). J. Nat. Hist. 17, 489 - 506.

Reese J.C and Carlson S.D. (1974). Scanning electron microscopy of final instar larval mouthparts of the black cutworm, Agrotis ipsilon. Ann. Entomol. Soc. Am., 67(03), 301 308.

Smith, P.E. (1911). Specific characters used in the genus Pseudococcus. Ann. Entomol. Soc. Am., 4, 309 - 327.

Takagi, S. (1990). Disc pores of Diaspididae: microstructure and taxonomic value (Homoptera: Coccoidea). Insecta Matsumurana, 44, 81 - 122.

Tan, S.J. and Zhang, Y.H. (1992). Ultrastructure of the wax gland in the male second instars of the white-wax insect, Ericeruspela Chavannes. Zool. Res., 13(03), 217 - 222.

Ubero-Pascal, N., Arnaldos, I., López-Esclapez, R. and García, M.D. (2010). Microscopy and forensic entomology. pp. 1548-1556. In: Méndez-Vilas, A. and Díaz, J.(Ed.). Microscopy: science, technology, applications and education. Microscopy Book Series No. 4. Formatex Research Center, Badajoz, Spain.

Ülgentürk, S. and Wilhem, G. (2001). Wax exuding disc-pores of Coccus hesperidum L. Parthenolecanium corni Bouché and Sphaerolecanium prunastri (Fonscolombe) (Hemiptera: Coccidae), pp. 15. In: Pellizzari, G. (Ed.). Programme and Abstracts. IX International Symposium on Scale Insect Studies, Padua, Italy, 82 pp.

Unruh, C.M. (2008). A taxonomic review of the Crypticerya species (Hemiptera: Coccoidea: Monophlebidae) of the southwestern United States and Mexico, including description of a new species from Baja California. Zootaxa, 1759, 1 - 42.

Unruh, C.M. and Gullan, P.J. (2008). Molecular data reveal convergent reproductive strategies in iceryine scale insects (Hemiptera: Coccoidea: Monophlebidae), allowing reinterpretation of morphology and a revised generic classification. Syst. Entomol. 33, 8 - 50.

Vahedi, H.A .and Mahfar, F.G. (2010). Scanning electron microscope observations on the multiloculardisc-pores and dermal projections of adult female Porphyrophora tritici and $P$. cynodontis. Entomol. Hellenica, 19, 76 - 81.

Waku, Y. and Manabe, Y. (1981). Fine structure of the wax gland in a scale insect, Eriococcus lagerstraemiae Kuwana (Homoptera: Eriococcidae). Appl. Entomol. Zool., 16(02), 94 - 102.

Zhang, Y. Xie, Y. Xue, J. Fu, X. and Liu, W. (2012). The structure of integument and wax glands of Phenacoccus fraxinus (Hemiptera: Coccoidea: Pseudococcidae). Zool. Res., 33(E1-2), E13-E17. doi: 10.3724/SP.J.1141.2012.E01-02E13. 
Zhang, Z. Shao, M. Qi, S. Guo, X. Ma, H. and Ren, H. (1988). Study on wax secretion capacity of the white wax insect (Ericeruspela Chavannes) in China. Zool. Res., 9(01), 93 97. 